\title{
The 12th International conference on scientometrics and informetrics
}

\author{
Jacqueline Leta $\cdot$ Birger Larsen • Ronald Rousseau • Wolfgang Glänzel
}

Received: 15 March 2010/Published online: 22 April 2010

(C) Akadémiai Kiadó, Budapest, Hungary 2010

The 12th International Conference on Scientometrics and Informetrics held in Rio de Janeiro (Brazil) in July 2009 was organised by BIREME/PAHO/WHO (Latin American and Caribbean Center on Health Sciences Information of the Pan American Health Organization/World Health Organization) and the Federal University of Rio de Janeiro (UFRJ), under the auspices of the International Society for Scientometrics and Informetrics (ISSI). ${ }^{1}$ The previous ten events in this series of biennial international conferences on scientometrics and informetrics have been held in Belgium (1987), Canada (1989), India (1991), Germany (1993), USA (1995), Israel (1997), Mexico (1999), Australia (2001), China (2003), Sweden (2005) and Spain (2007).

More than 230 participants from 40 countries of all continents attended the meeting, covering all relevant topics of present-day research in our field. For this special issue of the journal Scientometrics we have selected 19 original research papers, which are extended

\footnotetext{
${ }^{1}$ Leta, J. (2009), 12th International Conference of the International Society for Scientometrics and Informetrics in Rio de Janeiro, Brazil (July 14-17), ISSI Newsletter, 5 (3), 42-2 (accessible via: http://www.issi-society.info/archives/newsletter19.pdf).
}

\section{J. Leta}

Science Education Program, Medical Biochemistry Institute, Federal University of Rio de Janeiro (UFRJ), Rio de Janeiro, Brazil

B. Larsen

Royal School of Library and Information Science, Copenhagen, Denmark

R. Rousseau

KHBO (Association K.U. Leuven), Industrial Sciences and Technology, Oostende, Belgium

R. Rousseau

Department of Mathematics, K.U. Leuven, Leuven, Belgium

W. Glänzel $(\bowtie)$

Centre for R\&D Monitoring (ECOOM) and Department of MSI, K.U. Leuven, Leuven, Belgium e-mail: Wolfgang.Glanzel@econ.kuleuven.be

W. Glänzel

Hungarian Academy of Sciences, Institute for Science Policy Research, Budapest, Hungary 
versions of contributions orally presented at the conference, reflecting comments given by colleagues and referees during and after the conference. This selection covers all traditional and new topics of our field including scientometrics, informetrics, webmetrics, mapping and visualisation techniques, patent analysis and gender studies.

Finally, we would like to mention that the 13th conference of this series will be held in Durban, South Africa, in summer 2011. 